\title{
Seasonal Effects of Extreme Weather Events on Potential Extracellular Enzyme Activities in a Temperate Grassland Soil
}

\author{
Verena B. Hammerl ${ }^{1}$, Kerstin Grant ${ }^{2}$, Karin Pritsch ${ }^{3}$, Anke Jentsch ${ }^{4}$, Michael Schloter ${ }^{1}$, \\ Carl Beierkuhnlein ${ }^{2}$ and Silvia Gschwendtner ${ }^{1 *}$ \\ ${ }^{1}$ Research Unit Comparative Microbiome Analysis-Helmholtz Zentrum München, Neuherberg, Germany, ${ }^{2}$ Disturbance \\ Ecology, BayCEER, University of Bayreuth, Bayreuth, Germany, ${ }^{3}$ Institute of Biochemical Plant Pathology-Helmholtz Zentrum \\ München, Neuherberg, Germany, ${ }^{4}$ Chair of Biogeography, BayCEER, University of Bayreuth, Bayreuth, Germany
}

OPEN ACCESS

Edited by:

Hannes Schmidt,

Universität Wien, Austria

Reviewed by:

Alberto Canarini,

Universität Wien, Austria

Lucia Fuchslueger,

University of Antwerp, Belgium

*Correspondence:

Silvia Gschwendtner

silvia.gschwendtner@

helmholtz-muenchen.de

Specialty section:

This article was submitted to

Soil Processes,

a section of the journal

Frontiers in Environmental Science

Received: 21 August 2018

Accepted: 13 December 2018

Published: 22 January 2019

Citation:

Hammerl VB, Grant K, Pritsch K,

Jentsch A, Schloter M, Beierkuhnlein $C$ and Gschwendtner $S$

(2019) Seasonal Effects of Extreme

Weather Events on Potential

Extracellular Enzyme Activities in a

Temperate Grassland Soil.

Front. Environ. Sci. 6:157.

doi: 10.3389/fenvs.2018.00157
Magnitude and timing of precipitation events within the growing season might be decisive for alterations in potential extracellular enzyme activity (PEEA), with consequences for nutrient cycle, and carbon storage in grassland ecosystems. Pattern of PEEA catalyzing major steps of the carbon cycle ( $\beta$-glucosidase ( $\beta$-gls), cellobiohydrolase (cel), glucuronidase (glr), and xylosidase (xyl), soil respiration rates and extractable organic carbon were analyzed in response to increased intra-annual precipitation variability in a European, mesic temperate grassland. The field experiment was carried out in three subsequent years by simulating recurrent drought events combined with heavy rainfall either early or late in the growing season (spring or summer) by rainout shelters and irrigation systems. Our data indicated comparable effects of the drought settings independent from the timing of the drought. Both for the simulated spring- and summer drought a decrease of enzymatic activities was observed compared to the control plots, with B-gls activity after the summer drought being the only exception. However, response pattern toward rewetting differed depending on the seasonal timing of the drought being introduced. After spring drought, a fast recovery to control level was observed for PEEA of B-gls and xyl, whereas cel and glr activity remained constantly lower. Rewetting after summer drought induced an increase of all enzymatic activities to values even higher compared to the controls. Overall, our data indicate a high resilience of PEEA toward drought and rewetting events in grassland soils, which is modulated by the seasonal timing of the extreme weather events.

\footnotetext{
Keywords: climate change, potential extracellular enzyme activity, carbon cycle, extreme weather event, severe drought, rewetting, precipitation variability, seasonality
}

\section{INTRODUCTION}

Extreme weather events such as heavy rainfall or extreme drought are predicted to increase in frequency and magnitude as a consequence of climate change (O'Gorman and Schneider, 2009; IPCC, 2014). Results from several studies have suggested that the consequences of extreme events on ecosystem functioning will be much stronger than the effects of changes in mean values 
of temperature or precipitation (Easterling, 2000). Higher variability of soil water content as a consequence of extreme weather events, strongly affect activity pattern of all soil biota and in consequence major ecosystem services provided by soils (Meehl et al., 2000; Knapp et al., 2008).

Soil microorganisms including bacteria, archaea and fungi play a key role carbon and nutrient cycling of soils, as they produce important (exo)enzymes (Asmar et al., 1994) which catalyze the decomposition of organic matter (Richards, 1987; Ducklow, 2008). Several studies have indicated that exoenzymatic activities are the rate-limiting step in the decomposition of organic materials to dissolved organic matter (Schimel and Bennett, 2004; Bengtson and Bengtsson, 2007). Soil moisture is a key factor controlling microbial activity and thus soil $\mathrm{C}$ cycling (Borken and Matzner, 2009). If soils dry, microbial activity decreases (Manzoni et al., 2012) while extractable organic carbon (EOC) increases (Xiang et al., 2008; Homyak et al., 2018) as a result of physical disruption of soil aggregates (Homyak et al., 2018) and/or biological processes, e.g., lower microbial consumption under drought stress or enhanced microbial $\mathrm{C}$ allocation to cell walls, intra- and extra-cellular compounds and osmolyte production (Schimel and Schaeffer, 2012). Contradicting findings are reported for exoenzymatic activity which was observed being positively (Ochoa-Hueso et al., 2018) or negatively (Sardans and Peñuelas, 2010) affected by drought, with extent often being enzyme-specific. In contrast to drought, enhanced precipitation increases microbial activity (Barnard et al., 2015), resulting in increase of enzyme activity and decrease of EOC (Fierer and Schimel, 2003). However, when investigating the influence of drought and increased precipitation, most studies focused on events occurring at a defined timing during season. Thus, not much is known about to which extent the seasonal timing of the extreme event affects the response of microbial and enzymatic activity, although this might be an important factor. For example, Chou et al. (2008) observed that changes in the seasonal timing of rainfall significantly affected soil respiration, suggesting that $\mathrm{C}$ cycling in annual grasslands will be more affected by altered seasonal timing of precipitation than by changes in rainfall quantity.

These findings indicate that a simple assumption on the consequences of extreme weather events for the soil microbiome and its activity pattern is still not possible and most likely depends on various parameters like soil type, climatic conditions, management and timing of the event during season. Spring is the season with the best environmental conditions for plant and microbial activity (optimal water availability and temperature coinciding with the greatest litterfall of the year) (Ogaya and Peñuelas, 2004). Consequently, any disturbance will affect the ecosystem in the most productive, proliferative phase of the year, which might result in irreversible (negative) changes and longterm legacy effects. Thus, we hypothesize that extreme drought events will affect microbial activity and exoenzymatic activity more severely in spring compared to summer. To investigate this hypothesis, we analyzed potential extracellular enzyme activities (PEEAs) catalyzing major steps of the carbon cycle ( $\beta$-glucosidase, cellobiohydrolase, glucuronidase and xylosidase) as well as extractable organic carbon (EOC) and overall soil respiration in a semi-natural grassland, which was subjected to variabilities in precipitation at different time points of the season. Therefore, the experimental field was exposed for three consecutive years to two separate, yearly recurrent, drought treatments (extreme spring or summer drought), each followed by a heavy rain event. Effects were measured in all 3 years to exclude effects caused by natural variabilities of the climate and to assess a possible legacy effect of drought of the soil microbiome.

\section{MATERIALS AND METHODS}

\section{Study Site and Sampling}

The study was part of the EVENT II experiment which was established in a split plot design to test effects of altered precipitation regimes, warming, mowing, and fertilization on the ecosystem functions of semi-natural grassland (Jentsch and Beierkuhnlein, 2010; Grant et al., 2014). It is located at the Ecological-Botanical Garden of Bayreuth, Germany $\left(49^{\circ} 55^{\prime} 19^{\prime \prime} \mathrm{N}, 11^{\circ} 34^{\prime} 55^{\prime \prime} \mathrm{E}, 365 \mathrm{~m}\right.$ above sea level). The mean annual temperature was $8.2^{\circ} \mathrm{C}$ with a mean precipitation of $724 \mathrm{~mm}$ (1971-2000). The plant community was characterized as semi-natural-grassland dominated by tall grasses, especially Alopecurus pratensis and Arrhenatherum elatius. The soil texture was characterized as Gleysol with the upper $30 \mathrm{~cm}$ representing the homogenous and loamy Ap horizon (42 sand, 43 silt, 15\% clay), followed by a clayey Bg horizon. Topsoil has $\mathrm{pH}$ of $4.1(1 \mathrm{M}$ $\mathrm{KCl}$ ), total carbon content of $3.0 \%$, total nitrogen content of $0.2 \%$ (Glaser et al., 2013), permanent wilting point ( $\mathrm{pF}=4.2$ ) of 15 vol\% soil moisture content and field capacity $(\mathrm{pF}=1.8)$ of 40 vol\%.

In the current study, only experimental plots without fertilization or warming were considered. The experiment was performed for three consecutive years (2009-2011) simulating two separate annual drought treatments with (I) spring drought (D1, May-June), or (II) summer drought (D2, July-August), each followed by a heavy rain event (see Table S1). For each treatment, five plots, each $1.5 \times 1.5 \mathrm{~m}$ in size, have been set up and treated as independent replicates using latin square design. In addition, control plots were installed, resulting in 15 experimental plots in total. All plots were mowed twice a year (end of spring drought event (June) and end of growing season (September)), resembling local agricultural routines for extensively used grassland. Each drought period lasted for 42 days (duration was based on the statistically calculated local Bayreuth 1,000-year recurrent extreme event) and was realized using rainout shelters as described earlier (Walter et al., 2012). Briefly, the rainout shelters consisted of transparent polyethylene (PE) -foil clamped on a metal frame with a light-permeability of $90 \%$ for an optimal light perception, had a height of $2.5 \mathrm{~m}$, a base of $5.5 \times 7.5 \mathrm{~m}$ and were installed at $0.8 \mathrm{~m}$ height above soil to avoid overheating (no significant increase of near-surface air-temperature was observed (Kreyling et al., 2008). To quantify possible shading effects of rainout shelter, an additional roofartifact control plot receiving the same amount of water as uncovered control was installed under the rainout-shelters. As no difference in biomass production between roof-artifact and uncovered control was observed (Walter et al., 2012) shading 
effects could be excluded. In order to avoid water influx during ambient rainfall, a $1 \mathrm{~m}$ buffer zone at the edge of the sheltered plots remained unsampled. The uncovered control plots received ambient precipitation with additional water amounts to ensure that the weekly precipitation amount did not drop below the 30year weekly average (1971-2000, data: German Weather Service) to avoid natural occurring drought events. Thus, continuous water supply during the vegetation period (April-September) was realized. To ensure a constant amount of yearly precipitation over all plots, additional water was added to plots subjected to D1 and D2 4 times a year (Walter et al., 2012). Thus, each drought period was followed by a simulated heavy rain event (Table S1). Within these heavy rain events water amounts, the excluded amount of rainfall together with adjusted reference amount, were applied as one extreme event within 2 or 3 days. To prevent water run-off, irrigation was divided into two or three applications per day. To avoid lateral water flow, plastic sheet pilings were placed around each plot to a depth of -0.2 to $-0.25 \mathrm{~m}$.

Sampling was performed for each drought event in all three consecutive years (2009-2011) but with different time scales after rewetting to study effects for soil processes at different resolution. In detail, soil samples in the first sampling year (2009) were collected at the beginning of each drought treatment $(\mathrm{t} 0)$, at the last day of the drought ( $\mathrm{t} 1$ ), one ( $\mathrm{t} 2)$, two ( $\mathrm{t} 3$ ), and four ( $\mathrm{t} 4)$ weeks after rewetting. In 2010, samples were taken at the beginning (t0) and on the last day (t1) of each drought period, two (t2), four ( $\mathrm{t} 3$ ), and 6 weeks ( $\mathrm{t} 4$ ) (7 weeks for D2, respectively) after rewetting. To study the soil process during rewetting in more detail, in 2011 soil samples were taken on the last day of each drought (t1), two (t2), four ( $\mathrm{t} 3$ ) seven ( $\mathrm{t} 4)$, and ten ( $\mathrm{t} 5$ ) days after rewetting. At each sampling, three soil samples per plot were collected from 5 to $15 \mathrm{~cm}$ (the top $5 \mathrm{~cm}$ were discarded because of a thick rhizosphere layer) and pooled using a corer of $3 \mathrm{~cm}$ diameter. All samples were stored at $4^{\circ} \mathrm{C}$ until further handling within $48 \mathrm{~h}$.

\section{Soil Moisture}

Soil moisture was measured every hour using FD-sensors in each plot $\left(\mathrm{ECH}_{2} \mathrm{O}\right.$, Decagon devices, USA) in a depth of -0.02 to $-0.07 \mathrm{~m}$ undisturbed soil, respectively (Walter et al., 2012). The soil moisture data was calculated as mean per treatment $(n=5$ for each C, D1, and D2) and given in percentage of volume [vol \%] (Figure 1A). Annual precipitation amounts over the three sampling years are shown in Figure 1B. Soil moisture of samples used directly for enzyme activity measurements and correlations were determined by drying $2 \mathrm{~g}$ of fresh soil at $105^{\circ} \mathrm{C}$ for $24 \mathrm{~h}$ (Figures S1a,b-S3a,b).

\section{Extractable Organic Soil Carbon}

Extractable organic carbon (EOC) was determined in the years 2010 and 2011. Therefore, soil samples were extracted within 2 days after each sampling by shaking $10 \mathrm{~g}$ soil (fresh weight) in $40 \mathrm{~mL}$ of $0.01 \mathrm{M} \mathrm{CaCl} 2$ for $30 \mathrm{~min}$ on a rotary shaker (Gschwendtner et al., 2011). Afterwards, the soil suspension was filtered through $0.45 \mu \mathrm{m}$ pore-size filters (Whatman International LTD, VWR, Germany), and the extract were stored at $-20^{\circ} \mathrm{C}$ until further analyses. EOC contents were determined with a total organic carbon analyzer DIMATOC 2000 (DIMATEC Analysentechnik GmbH, Germany) by catalytic high-temperature oxidation.

\section{Soil Respiration}

In situ rates of soil respiration were measured using a portable $\mathrm{CO}_{2}$ infrared gas analyzer (EGM-4, PP Systems, USA) linked to a soil respiration chamber (SRC-1, PP System, USA). For plot preparation, permanent polyvinylchloride (PVC) collars $(10 \mathrm{~cm}$ diameter, $5 \mathrm{~cm}$ height) were installed in every plot at the beginning of the vegetation period 2010. The collars had a $1 \mathrm{~cm}$ edge above soil surface. This should realize a closed system when the soil respiration chamber was placed on the collar during measurement. The day before each measurement, aboveground vegetation was removed from the collar. The soil respiration chamber was placed for $4 \mathrm{~min}$ on the collar of every plot, averaging previous approaches (Sowerby et al., 2008; Saner et al., 2009). For statistical analyses the soil respiration rate value at second 240 of each measurement were taken, as it approached a constant value after $240 \mathrm{~s}$ following more or less a quadratic relationship. An internal fan realized the even distribution of air within the chamber. The infrared gas analyzer monitored the built up of $\mathrm{CO}_{2}$ within the system. The rates of soil respiration were determined by fitting a quadratic equation to the change in $\mathrm{CO}_{2}$ concentration with time. The soil respiration rates $\left[\mathrm{g} \mathrm{CO}_{2}\right.$ $\mathrm{m}^{-2} \mathrm{~h}^{-1}$ ] were quantified at the same date and time (8-12 a.m.) as soil sampling was performed in 2010, except for August 17th (2 weeks after summer drought ( $\mathrm{t} 2)$ ). At this date the measurement of soil respiration rates was not possible due to rainfall. Therefore, data of August 11 and 25th were added to this data set (t2a and $\mathrm{t} 2 \mathrm{~b})$.

\section{Potential Extracellular Enzyme Activities (PEEA)}

PEEAs were determined as described in detail by Pritsch et al. (2005) using methylumbelliferone (MUF) labeled substrates (Sigma-Aldrich Chemicals, Germany) and black microplates (VWR, Germany). Briefly, $100 \mu \mathrm{L}$ soil suspension (400 mg soil mixed with $40 \mathrm{~mL}$ sterile distilled water for $15 \mathrm{~min}$ ) was incubated with $20 \mu \mathrm{L}$ of the respective MUF labeled enzyme substrate. Substrate saturation concentration and incubation time for each enzyme was determined in pre-experiments as follows: $\beta$-glucosidase ( $\beta$-gls; EC 3.2.1.21) $500 \mu \mathrm{M}$ and $120 \mathrm{~min}$, cellobiohydrolase (cel; EC 3.2.1.91) $400 \mu \mathrm{M}$ and $120 \mathrm{~min}$, glucuronidase (glr; EC 3.2.1.31) $500 \mu \mathrm{M}$ and $120 \mathrm{~min}$ and xylosidase (xyl; EC 3.2.1.37) $500 \mu \mathrm{M}$ and $60 \mathrm{~min}$. After incubation, $100 \mu \mathrm{L}$ Tris buffer $(2.5 \mathrm{M}, \mathrm{pH}>10)$ was added to stop enzyme reaction and to increase $\mathrm{pH}$ for fluorescence measurements (Pritsch et al., 2005). Auto-fluorescence of the soil or quenching of the fluorescence signal influenced by the soil was accounted for by performing additional tests using $50 \mu \mathrm{L}$ of soil suspension and $100 \mu \mathrm{L}$ of 300 pmol MUF instead of substrate. Fluorescence measurements were performed on a spectrofluorometer (SpectraMax GEMINI EM, USA) at excitation / emission wavelengths of $365 / 450 \mathrm{~nm}$. Released amounts of MUF were calculated based on the autofluorescence, 


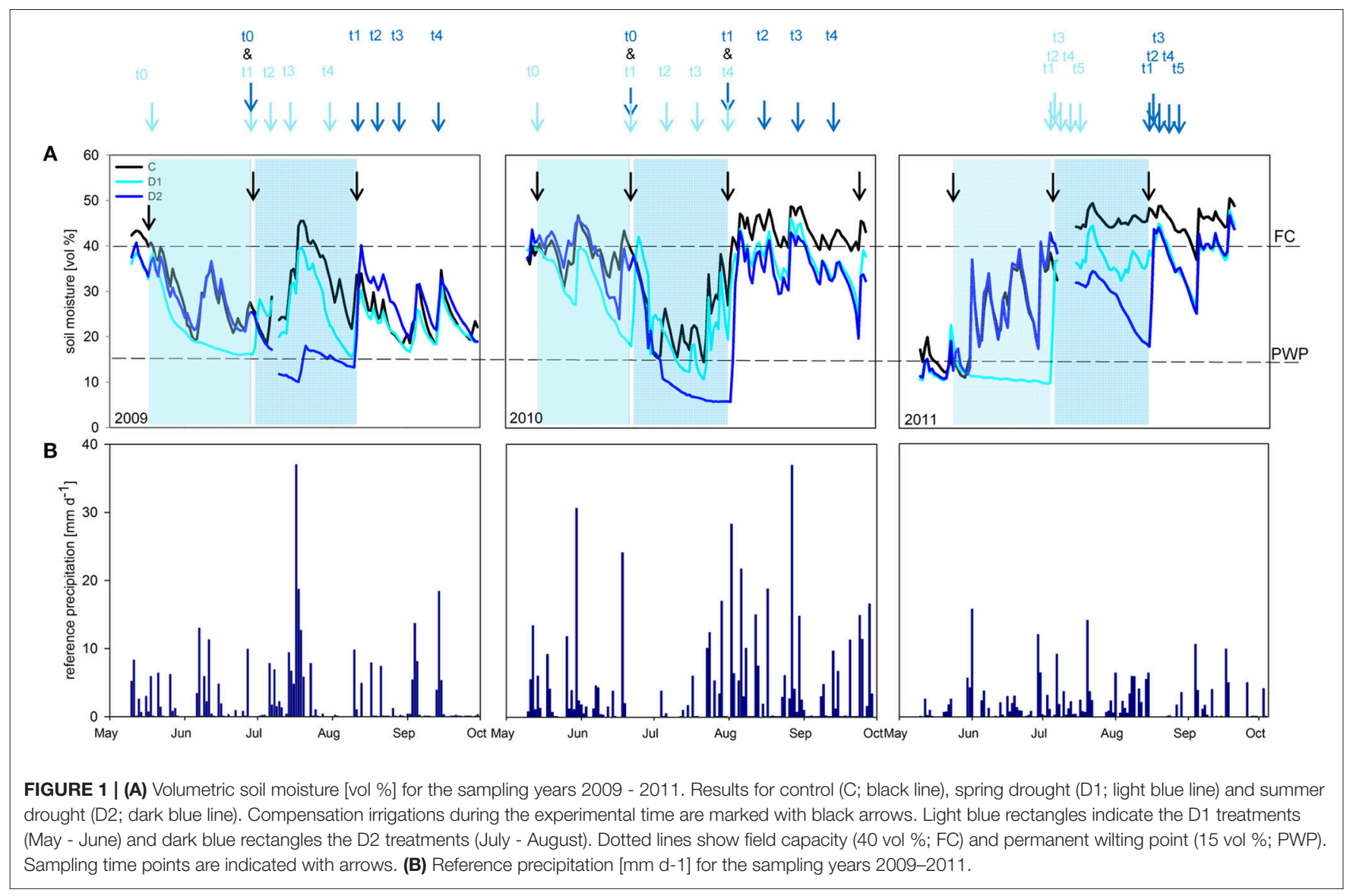

quenching and calibration curves and expressed as PEEA in pmol per gram soil dry weight per hour $\left[\mathrm{pmol} \mathrm{g}^{-1} \mathrm{dw} \mathrm{h}^{-1}\right]$ and measured for the three consecutive years.

\section{Statistical Analysis}

Analysis of variance (ANOVA) based on linear mixed effect models was performed to test for significant effects of weather manipulation on the response variables while taking the location coordinates of the plots within the latin square design into account by adding row and column as random factors to the model. Due to varying sampling scheme, data of each year was analyzed separately. When analyzing repeated measurements, sampling date as further random factor was added. To validate the linear mixed effects models, residual vs. fitted plots and plots showing sample quantiles vs. theoretical quantiles based on the model were tested for homogenous variance and normal distribution of residuals (Rosenblad, 2009). If either conditions of normality were not met or homogeneity of variance had to be improved, data was log transformed. In all tests the level of significance was set to $p=0.05$. All statistical analyses were performed using the $\mathrm{R}$ version 3.1.3 ( $\mathrm{R}$ Core Team, 2012) including the package nlme 3.1-120 for calculation of linear mixed effect models (Pinheiro et al., 2011). To link enzyme activity to soil moisture, EOC and sampling date (in form of day of year to quantify seasonal influence), boosted regression tree analysis was performed in R, using a default bag fraction of 0.5 , a Gaussian error distribution, a learning rate of 0.001 and a tree complexity of 3 to model enzyme activity along environmental parameters and time. All models were fitted using gbm package version 1.6-3.1 plus a custom code written by J. Leathwick and J. Elith (Supplementary Material to Elith et al., 2008).

\section{RESULTS}

\section{Soil Moisture}

Simulated spring and summer drought periods resulted in reduction of volumetric soil water content compared to control plots in all three sampling years (Figure 1; Table S2). Subsequent rewetting increased soil moisture to control level again. In 2010, an ambient heavy rain event during the D1 treatment caused an increase of the ground water level and therefore higher soil water content in the middle of June. In 2009 and 2010 soil moisture did not drop below permanent wilting point (PWP) during the spring drought (D1) but during the summer drought (D2). In contrast, in 2011 soil moisture content of D1 decreased below PWP, whereas D2 remained above PWP.

\section{Extractable Organic Carbon}

EOC was not affected by drought or rewetting in spring 2010 (Table 1) and remained stable over the experimental period $\left(28.48 \pm 5.58 \mu \mathrm{g} \mathrm{g}^{-1} \mathrm{dw}\right.$ for $\mathrm{C}$ and $31.32 \pm 7.88 \mathrm{~g}^{-1} \mathrm{dw}$ 
TABLE 1 | Extractable organic carbon (EOC) of grassland plots in 2010 [ $\mu \mathrm{g} \mathrm{g}^{-1} \mathrm{dw}$ ] for different precipitation variabilities for spring drought (D1) and summer drought (D2); given are mean values and standard errors, each $n=5$.

\begin{tabular}{|c|c|c|c|c|c|}
\hline \multicolumn{3}{|c|}{ Spring } & \multicolumn{3}{|c|}{ Summer } \\
\hline Time & Treatment & EOC & Time & Treatment & EOC \\
\hline 10.05 .2010 & C & $19.53( \pm 1.55)$ & 21.06 .2010 & C & $32.15( \pm 2.02)$ \\
\hline (t0) & D1 & $16.94( \pm 1.34)$ & (t0) & D2 & $46.32( \pm 4.78)$ \\
\hline 21.06 .2010 & C & $32.15( \pm 2.02)$ & 02.08.2010 & C & $26.87( \pm 2.31)^{\star}$ \\
\hline (t1) & D1 & $38.75( \pm 4.35)$ & $(\mathrm{t} 1)$ & D2 & $64.70( \pm 13.85)^{\star}$ \\
\hline 06.07 .2010 & C & $27.05( \pm 2.62)$ & 17.08 .2010 & C & $46.76( \pm 4.04)$ \\
\hline (t2) & D1 & $30.73( \pm 2.46)$ & (t2) & D2 & 53.87 (土3.95) \\
\hline 20.07.2010 & C & 27.85 ( \pm 2.94$)$ & 06.09.2010 & C & $63.57( \pm 10.25)$ \\
\hline (t3) & D1 & $28.47( \pm 2.63)$ & (t3) & D2 & $55.71( \pm 9.45)$ \\
\hline 02.08 .2010 & C & $26.87( \pm 2.31)$ & 20.09 .2010 & C & $42.93( \pm 4.30)$ \\
\hline (t4) & D1 & $27.31( \pm 2.66)$ & $(\mathrm{t} 4)$ & D2 & $43.85( \pm 4.00)$ \\
\hline
\end{tabular}

Significant differences $(p<0.05)$ between control $(C)$ and treatment are marked with asterisk $\left(^{*}\right)$.

for D1). In contrast, EOC after summer drought was 2-fold higher $\left(64.70 \pm 13.9 \mu \mathrm{g} \mathrm{g}^{-1} \mathrm{dw}\right)$ compared to control samples $\left(26.87 \pm 2.31 \mu \mathrm{g} \mathrm{g}^{-1} \mathrm{dw}\right)$ at $\mathrm{t} 1$ but decreased to the control level within two 2 weeks after rewetting (Table 1). Similar trends were observed in 2011 for the high- resolution sampling (Table S3).

\section{Soil Respiration}

Soil respiration was measured as proxy of microbial activity in 2010 (Table 2). Due to rainfall we could not measure soil respiration at August 17th (2 weeks after summer drought) and instead included data of August 11 (t2a) and August 25th (t2b) to the dataset. Overall, soil respiration ranged from $0.378 \mathrm{~g} \mathrm{CO}_{2}$ $\mathrm{m}^{-2} \mathrm{~h}^{-1}$ (summer, $\mathrm{C}, \mathrm{t} 4$ ) to $0.852 \mathrm{~g} \mathrm{CO}_{2} \mathrm{~m}^{-2} \mathrm{~h}^{-1}$ (spring, $\mathrm{D} 1, \mathrm{t} 2$ ) and was not affected by the drought events but showed a temporarily increase compared to control plots 1 week after summer drought rewetting ( $\mathrm{t} 2 \mathrm{a})$.

\section{Potential Extracellular Enzyme Activities}

PEEA showed no differences between controls and plots subjected to drought and rewetting at the beginning of the experiment ( $\mathrm{t} 0$ ) in the first two sampling years (Figure 2; Figure S1). As the observed treatment response was similar in all years, results of 2010 are exemplarily discussed in detail in the following. As expected, all measured PEEAs were slightly reduced at the end of the spring drought compared to the respective controls (Figure 2A). After summer drought, a similar pattern was observed with reduced PEEAs for cel, glr, and xyl compared to controls at $\mathrm{t}$, while $B$-gls showed no drought response (Figure 2B).

Subsequent rewetting after the spring drought (D1) resulted in fast increase of $B$-gls and xyl activities to control level. For both cel and glr no rewetting effect was observed and PEEA was constantly lower compared to control plots until t4 $(p<$ 0.05). Rewetting after summer drought (D2) induced higher activity for all measured PEEAs compared to the controls at $\mathrm{t} 2$. These differences were also visible at the later sampling time point $\mathrm{t} 3$; only at the last sampling time point ( $\mathrm{t} 4$ ) activity levels between control and affected plots were comparable. Data of high resolution sampling after rewetting in 2011 suggest that the increase in enzyme activity to control level after both drought treatments occurred already within the first four (spring) and two (summer) days after rewetting (Figure S2). In all sampling years, PEEA was significantly correlated with soil moisture for spring as well as summer drought treatment (except cel and glr in spring 2009) (Figure 3; Figures S3a,b). Boosted regression tree analysis including data of all years confirmed that soil moisture had the strongest influence on enzyme activity, explaining 53-79\% of the predictive data variance (Table S4), followed by seasonal effect. Season showed higher influence on PEEA after mid of July which indicates a higher sensitivity of enzymes later in the season and corresponds to the higher drought and rewetting responses observed in D2.

\section{DISCUSSION}

\section{Impact of Drought Manipulations}

Extractable organic carbon increased significantly during both spring and summer drought treatments in all years with one exception: spring 2010. However, it is most likely that this missing increase is a consequence of an ambient heavy rain event that occurred in the middle of June 2010, resulting in an increase in ground water level and thus higher soil moisture during D1 treatment. Accumulation of soil EOC after drought was reported previously (Xiang et al., 2008; Homyak et al., 2018) and might have been triggered by biological processes, e.g., enhanced microbial $\mathrm{C}$ allocation to cell walls, exopolymeric substances like EPS and/or osmolyte production to adapt to dry conditions (Schimel and Schaeffer, 2012; Warren, 2016). Moreover, microorganisms under oxidative stress are known to increase production of exoenzymes to fulfill their intracellular C demand by decomposing plant litter and thus acquiring resources that are unavailable otherwise (Bouskill et al., 2016). In contrast, all enzymatic activities were negatively affected by the drought treatments in the present study which suggests that increased EOC after drought is not a result of (microbe-mediated) 
TABLE 2 | Soil respiration rates [ $\mathrm{g} \mathrm{CO}_{2} \mathrm{~m}^{-2} \mathrm{~h}^{-1}$ ] of grassland in 2010 under different precipitation variabilities for spring drought (D1) and summer drought (D2); given are mean values and standard error of measuring dates, each $n=5$; on 17th August soil respiration could not be monitored due to ambient rainfall, therefore, 11 th August (t2a) and 25th August (t2b) were analyzed; no significant effects were observed.

\begin{tabular}{|c|c|c|c|c|c|}
\hline \multicolumn{3}{|c|}{ Spring } & \multicolumn{3}{|c|}{ Summer } \\
\hline Time & Treatment & Soil respiration & Time & Treatment & Soil respiration \\
\hline 10.05 .2010 & C & $0.462( \pm 0.04)$ & 21.06 .2010 & C & $0.562( \pm 0.02)$ \\
\hline (tO) & D1 & $0.482( \pm 0.04)$ & (t0) & D2 & $0.672( \pm 0.05)$ \\
\hline 21.06 .2010 & C & $0.562( \pm 0.02)$ & 02.08.2010 & C & $0.746( \pm 0.06)$ \\
\hline (t1) & D1 & $0.674( \pm 0.04)$ & $(\mathrm{t} 1)$ & D2 & $0.674( \pm 0.06)$ \\
\hline 06.07 .2010 & C & $0.728( \pm 0.05)$ & 11.08 .2010 & C & $0.636( \pm 0.07)$ \\
\hline \multirow[t]{3}{*}{ (t2) } & D1 & $0.852( \pm 0.14)$ & (t2a) & D2 & $0.846( \pm 0.10)$ \\
\hline & & & 25.8.2010 & C & $0.626( \pm 0.05)$ \\
\hline & & & (t2b) & D2 & $0.800( \pm 0.10)$ \\
\hline 20.07.2010 & C & $0.842( \pm 0.01)$ & 06.09.2010 & C & $0.502( \pm 0.02)$ \\
\hline (t3) & D1 & $0.816( \pm 0.13)$ & (t3) & D2 & $0.568( \pm 0.07)$ \\
\hline 02.08 .2010 & C & $0.746( \pm 0.06)$ & 20.09 .2010 & C & $0.378( \pm 0.03)$ \\
\hline (t4) & D1 & $0.726( \pm 0.09)$ & $(\mathrm{t} 4)$ & D2 & $0.406( \pm 0.05)$ \\
\hline
\end{tabular}

biochemical but physical soil organic matter decomposition and/or decreased diffusion and loss of connectivity of the soil pre-system (reviewed by Moyano et al., 2013). This is in line with Homyak et al. (2018), suggesting that physical processes leading to increased breakup of soil aggregates during dryingrewetting cycles and thus to substrate mobilization (Xiang et al., 2008) mainly contribute to EOC accumulation in dry soils. Besides, increase of EOC might be a result of reduced microbial consumption due to lower activity and/or limited substrate diffusion, too (reviewed by Moyano et al., 2013). Independent from the timing of the drought setting, PEEA was reduced after drought. The only exception was the ß-gls activity after the summer drought simulation, which was not affected by the treatment. This indicates that at least some microbes which are able to express those enzymes are tolerating lower water contents in soil or B-glucosidase is particularly robust and works as extracellular enzyme without the need of active microbes. ß-glucosidases catalyze the hydrolysis of the glycosidic bonds to terminal non-reducing residues in beta- $\mathrm{D}$-glucosides and oligosaccharides, with release of glucose (Lehninger et al., 2000). $\beta$-glucosidase is responsible for the regulation of the entire cellulose hydrolysis process by easing cellobiose-mediated suppression and producing the final product glucose (Singhania et al., 2013). So far, different $\beta$-glucosidases have already been characterized from bacteria, archaea and eukaryotes in a large variety of environments (Wierzbicka-Wos et al., 2013). Thus, not surprisingly high $B$-glucosidase activities were also found in arid to semiarid environments (Cañizares et al., 2011), indicating a high tolerance of this enzyme to drought stress, which is in line with the present study. However, the original substrate for the $ß$-glucosidases most likely will not be cellulose, as microbes which express cellobiohydrolases (catalyzing the initial step of cellulose degradation) are strongly affected ones in both drought settings. It is well-known that some $ß$-glucosidases are also capable to use galactose as an alternative substrate (Cairns and Esen, 2010). So, besides the obvious functional redundancy of microbes which are capable to express $ß$-glucosidases also the functional flexibility of the enzyme itself might induce the observed stability pattern toward drought stress at least in summer.

Besides cellobiohydrolase, PEEA of glucuronidase, and xylosidase were sensitive to severe drought events. These enzymes are involved in the breakdown and degradation of hemicellulose and are produced if no easier degradable carbon compounds are available (Stemmer et al., 1998). Both enzymes were negatively affected by drought, which is in accordance with previous studies (Sardans and Peñuelas, 2010; Sanaullah et al., 2011; Brockett et al., 2012). Mainly for xylosidase, functional redundancy of the respective microbes is low and mostly connected to Bacilli (Pontonio et al., 2016), although also some fungal xylosidases have been described (Pérez-González et al., 1998; Larraya et al., 2000). Glucuronidases have been mostly described as proteobacterial origin and have been mostly associated with microbes typically occurring in the rhizosphere (Castrillo et al., 2017). Thus, reduced plant performance as result of induced drought treatments as shown previously in EVENT II (Walter et al., 2012; Grant et al., 2014) and the associated altered exudation rates, might have affected this group of microbes negatively in addition to the direct drought stress.

\section{Response to Rewetting}

We expected rewetting to increase microbial activity and consequently also potential extracellular enzyme activity. Interestingly, no increase in soil respiration which would indicate higher microbial activity was observed after rewetting. However, this must not necessarily exclude increased microbial activity. It might be speculated that the $\mathrm{CO}_{2}$ peak was only temporarily and thus was missed due to selected measurement time points (earliest 1 week after rewetting). Given that EOC concentration was reduced to control level already at the first sampling after rewetting, it is likely that microorganisms 


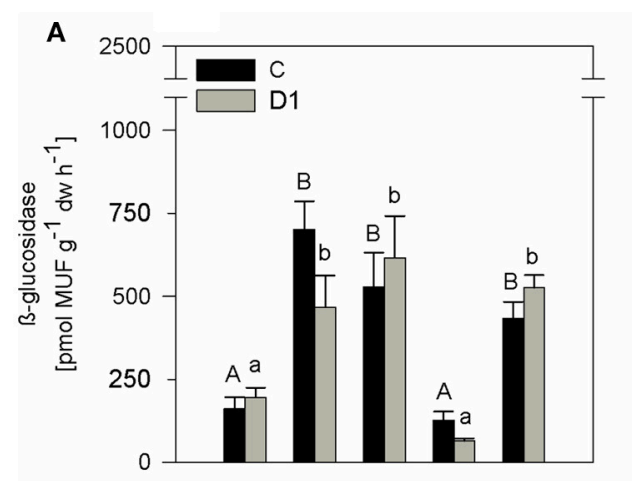

B
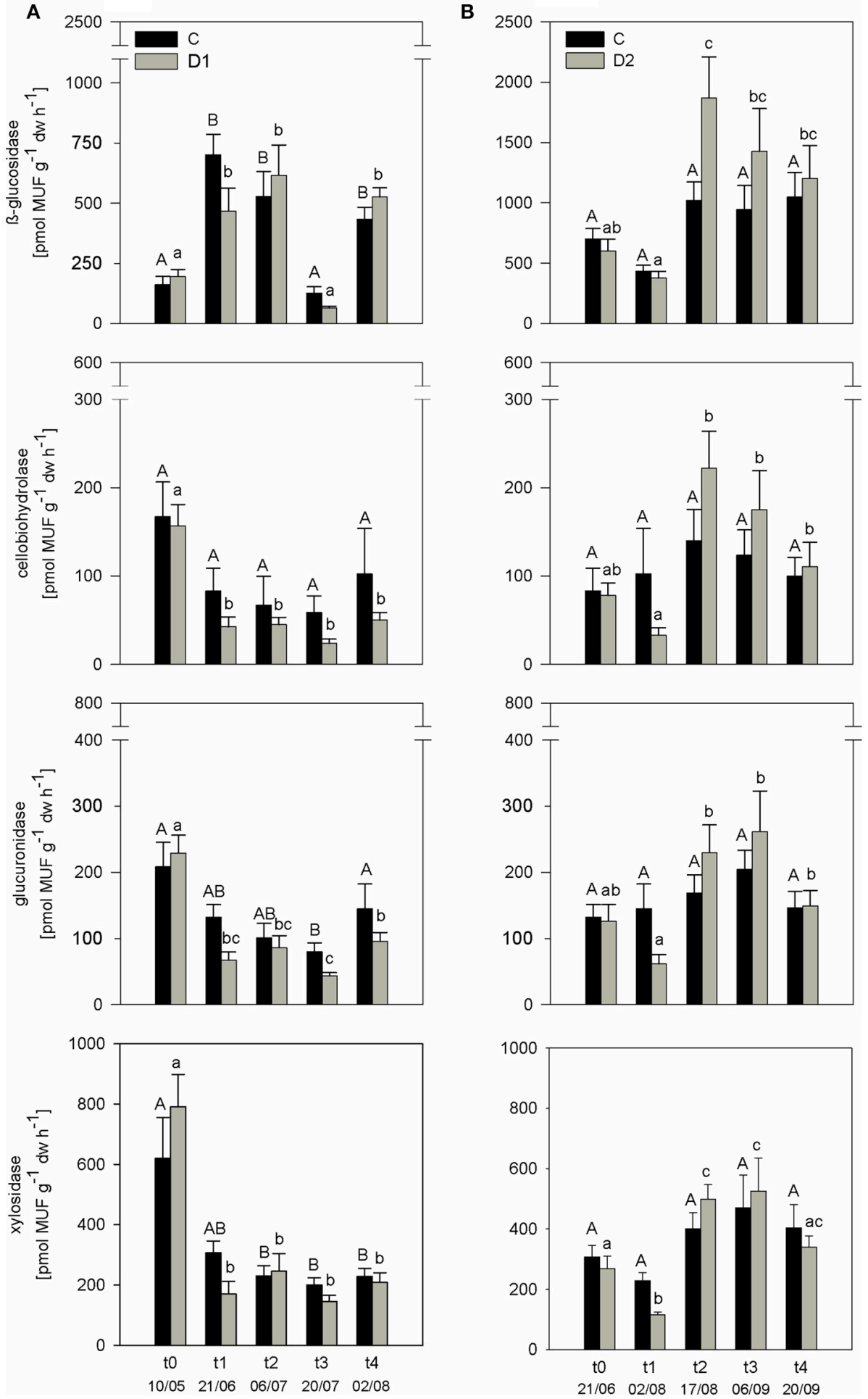

FIGURE 2 | Potential extracellular enzyme activities (PEEA) [pmol MUF $\mathrm{g}^{-1} \mathrm{~h}^{-1}$ ] of 2010 under different precipitation variabilities for control (C, black bars) and drought/rewetted plots (D, gray bars) at (A) spring drought and (B) summer drought simulation; given are mean values and standard error of measuring dates, each $n$ $=5$; drought treatment occurred from t0 to t1; significant differences $(p<0.05)$ between $\mathrm{C}$ and $\mathrm{D}$ are marked with asterisks; significant differences $(p<0.05)$ among sampling times are indicated by different letters. 

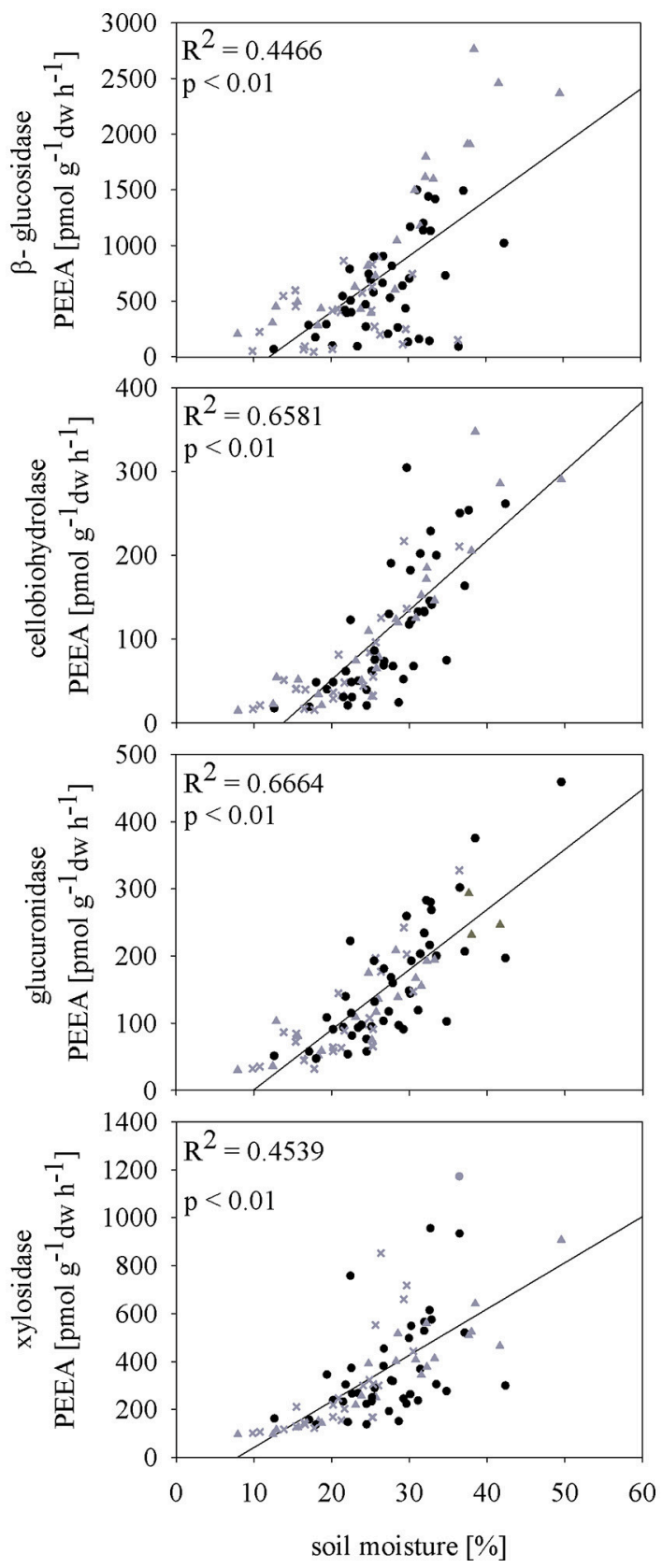

FIGURE 3 | Pearson correlation of soil moisture [vol \%] and potential extracellular enzyme activities (PEEA) [pmol MUF $\mathrm{g}^{-1} \mathrm{~h}^{-1}$ ] of 2010 under different precipitation variabilities (control (C) black dots, spring drought (D1) gray crosses and summer drought (D2) gray triangles).

respond rapidly to increased soil moisture, mineralizing labile carbon substrates within a few days as shown previously (Fierer and Schimel, 2003). As expected, potential enzyme activity responded positively to rewetting in all 3 years, with an extent being enzyme-specific. While cellobiohydrolase and glucuronidase did not recover when drought simulation occurred in spring, all enzymes showed a positive rewetting effect after summer drought. This indicates that beside soil moisture, which was the main predictor of enzyme activity, also the timing of the drought/rewetting event influenced PEEA to a remarkable extent: enzymes were more severely affected in spring and were more sensitive to rewetting later in the season, corresponding with higher responses found in D2 compared to D1 (booted regression tree analysis).

\section{Seasonal Effects on Extreme Events}

Our results indicate that not only drought/rewetting itself but also the seasonal timing of the extreme event remarkably affected exoenzymatic activity: while reduced PEEA recovered after summer drought rewetting, the negative effect of spring drought was much more pronounced, resulting in irreversible lower cel and glr activity despite rewetting. The observed seasonal dependency might be explained by the fact that spring drought affected plant growth in the most productive, proliferative phase of the year. This is in line with Grant et al. (2017) who reported that plant community composition in EVENT II was differently altered by drought events occurring at different growing seasons, leading to pronounced aboveground changes in plant biomass. Furthermore, available dead root biomass and/or root length is known to be lower in early summer compared to late summer, resulting in lower EOC concentration (Bardgett et al., 2005; Walter et al., 2012; Chaparro et al., 2013; Regan et al., 2017). Although plant biomass was not investigated in the present study, a decline of EOC after spring drought was observed. Therefore, it could be speculated that dead root biomass might have been reduced, too, leading to a lower overall amount of dead plant biomass available for decomposition and thus more severe effects of extreme events on PEEA in spring compared to summer. Another explanation for differences between both seasons might also be given by mowing at end of June, which means after spring but before summer drought simulation. Mowing is common agricultural practice to stimulate growth of aboveground biomass during late growing season. Besides, when dead plant biomass is not removed, it introduces new carbon and nutrient sources into the soil which could be used by plants and microbes after rewetting via decomposition by exoenzymes. Therefore, more substrate is available at D2 which might have contributed to the stronger PEEA increase after summer drought rewetting compared to spring drought rewetting. These findings suggest that the seasonal difference in the availability of dead plant biomass was an important driver for the effects of drought and recovery of PEEA in addition to the water supply. Panikov (1999) gives further evidence that indirect effects of climatic changes, like shifts in plant community structure, quantity and quality of plant litter or the supply of nutrients and the modification in physical and chemical characteristics affect microorganisms in a stronger way than direct climatic changes.

\section{CONCLUSION}

Whereas, our results indicate comparable negative effects of simulated drought in both seasons, positive response of PEEA toward rewetting was much more pronounced when drought occurred later in the season. This seasonal effect might be explained by differences in the availability of dead plant biomass serving as substrate for decomposition. Consequently, the seasonality of extreme events has to be much more considered 
in future studies and incorporated in predicted climate scenarios to improve existing models. However, no long-term changes in potential extracellular enzyme activities, soil respiration rates or extractable organic carbon were implemented by drought and heavy rain events within this 3 years study. Consequently, grassland soils might be highly resilient or might have buffered drought and rewetting effects in an effective way. This general fast response to rewetting of the dry soils lead to the assumption that microbial community in this temperate grassland soil is resilient to both, drought and rewetting stress or that there was a gradual adaptation to the changed plant community composition over 3 years. As microbes are important drivers of nutrient cycling, we recommend including analysis of plant and soil microbial community composition as well as its functional potential in future studies in order to get a better understanding of grassland ecosystem's response toward drought and rewetting. Overall, our results show the need for a new integrative framework including both abiotic and biotic factors to predict future climate change impacts on terrestrial ecosystems, including the seasonal effect on ecosystem's response to extreme events.

\section{AUTHOR CONTRIBUTIONS}

VH collected the soil samples, analyzed the date and wrote the manuscript. KG, SG, and MS made guidance for the writing of

\section{REFERENCES}

Asmar, F., Eiland, F., and Nielsen, N. E. (1994). Effect of extracellular-enzyme activities on solubilization rate of soil organic nitrogen. Biol. Fertil. Soils 17, 32-38. doi: 10.1007/BF00418669

Bardgett, R. D., Bowman, W. D., Kaufmann, R., and Schmidt, S. K. (2005). A temporal approach to linking aboveground and belowground ecology. Trends Ecol. Evol. 20, 634-641. doi: 10.1016/j.tree.2005.08.005

Barnard, R. L., Osborne, C. A., and Firestone, M. K. (2015). Changing precipitation pattern alters soil microbial community response to wet-up under a Mediterranean-type climate. ISME J. 9, 946-957. doi: 10.1038/ismej.2014.192

Bengtson, P., and Bengtsson, G. (2007). Rapid turnover of DOC in temperate forests accounts for increased $\mathrm{CO} 2$ production at elevated temperatures. Ecol. Lett. 10, 783-790. doi: 10.1111/j.1461-0248.2007.01072.x

Borken, W., and Matzner, E. (2009). Reappraisal of drying and wetting effects on $\mathrm{C}$ and $\mathrm{N}$ mineralization and fluxes in soils. Glob. Chang. Biol. 15, 808-824. doi: 10.1111/j.1365-2486.2008.01681.x

Bouskill, N. J., Wood, T. E., Baran, R., et al. (2016). Belowground Response to Drought in a Tropical Forest Soil. II. Change in Microbial Function Impacts Carbon Composition. Front. Microbiol. 7, 323-323. doi: 10.3389/fmicb.2016.00323

Brockett, B. F. T., Prescott, C. E., and Grayston, S. J. (2012). Soil moisture is the major factor influencing microbial community structure and enzyme activities across seven biogeoclimatic zones in western Canada. Soil Biol. Biochem. 44, 9-20. doi: 10.1016/j.soilbio.2011.09.003

Cairns, K. J. R., and Esen, A. (2010). B-Glucosidases. Cell. Mol. Life Sci. 67, 3389-3405. doi: 10.1007/s00018-010-0399-2

Cañizares, R., Benitez, E., and Ogunseitan, O. A. (2011). Molecular analyses of $\beta$-glucosidase diversity and function in soil. Eur. J. Soil Biol. 47, 1-8. doi: 10.1016/J.EJSOBI.2010.11.002

Castrillo, G., Teixeira, P. J. P. L., Paredes, S. H., et al. (2017). Root microbiota drive direct integration of phosphate stress and immunity. Nature 543:513. doi: 10.1038/nature21417 the manuscript, revised the manuscript and helped analyzing the data. KG supervised the statistical analyses. KP, AJ, CB, and MS reviewed the initial design of the experiment and supervised the experiment.

\section{FUNDING}

This study was funded by the Bavarian Climate Programme 2020 of the Bavarian State Ministry of Sciences, Research and Arts within the FORKAST research cooperation Impact of Climate on Ecosystems and Climatic Adaptation Strategies.

\section{ACKNOWLEDGMENTS}

We thank the German Weather Service for the long-term precipitation data. Further, we thank G. Hufnagel for the excellent technical support in measuring soil chemical parameters. We also thank the reviewers for their helpful comments on an earlier version of this manuscript.

\section{SUPPLEMENTARY MATERIAL}

The Supplementary Material for this article can be found online at: https://www.frontiersin.org/articles/10.3389/fenvs. 2018.00157/full\#supplementary-material

Chaparro, J. M., Badri, D. V., Bakker, M. G., Sugiyama, A., Manter, D. K., and Vivanco, J. M. (2013). Root exudation of phytochemicals in arabidopsis follows specific patterns that are developmentally programmed and correlate with soil microbial functions. PLoS ONE 8:e55731. doi: 10.1371/journal.pone.0055731

Chou, W. W., Silver, W. L., Jackson, R. D., Thompson, A. W., and AllenDiaz, B. (2008). The sensitivity of annual grassland carbon cycling to the quantity and timing of rainfall. Glob. Chang. Biol. 14, 1382-1394. doi: 10.1111/j.1365-2486.2008.01572.x

Ducklow, H. (2008). Microbial services: challenges for microbial ecologists in a changing world. Aquat. Microb. Ecol. 53, 13-19. doi: 10.3354/ame01220

Easterling, D. R. (2000). Climate extremes: observations, modeling, and impacts. Science 289, 2068-2074. doi: 10.1126/science.289.5487.2068

Elith, J., Leathwick, J. R., and Hastie, T. (2008). A working guide to boosted regression trees. J. Anim. Ecol. 77, 802-813. doi: 10.1111/j.1365-2656.2008.01390.x

Fierer, N., and Schimel, J. P. (2003). A proposed mechanism for the pulse in carbon dioxide production commonly observed following the rapid rewetting of a dry soil. Soil Sci. Soc. Am. J. 67, 798-805. doi: 10.2136/sssaj2003.0798

Glaser, B., Jentsch, A., Kreyling, J., and Beierkuhnlein, C. (2013). Soil-moisture change caused by experimental extreme summer drought is similar to natural inter-annual variation in a loamy sand in Central Europe. Plant Nutr. Soil Sci. 176, 27-34. doi: 10.1002/jpln.201200188

Grant, K., Kreyling, J., Beierkuhnlein, C., and Jentsch, A. (2017). Importance of seasonality for the response of a mesic temperate grassland to increased precipitation variability and warming. Ecosystems 20, 1-14. doi: 10.1007/s10021-017-0122-3

Grant, K., Kreyling, J., Dienstbach, L. F. H., Beierkuhnlein, C., and Jentsch, A. (2014). Water stress due to increased intra-annual precipitation variability reduced forage yield but raised forage quality of a temperate grassland. Agric. Ecosyst. Environ. 186, 11-22. doi: 10.1016/j.agee.2014.01.013

Gschwendtner, S., Esperschütz, J., Buegger, F., Reichmann, M., Müller, M., Munch, J. C., et al. (2011). Effects of genetically modified starch metabolism in potato plants on photosynthate fluxes into the rhizosphere and on 
microbial degraders of root exudates. FEMS Microb. Ecol. 76, 564-575. doi: 10.1111/j.1574-6941.2011.01073.x

Homyak, P. M., Blankinship, J. C., Slessarev, E. W., Schaeffer, S. M., Manzoni, S., and Schimel, J. P. (2018). Effects of altered dry season length and plant inputs on soluble soil carbon. Ecology 99, 2348-2362. doi: 10.1002/ecy.2473

IPCC (2014). Climate Change 2014: Contribution of Working Group I, II, III to the Fifth Assessment Report of the Intergorvernmental Panel on Climate Change.

Jentsch, A., and Beierkuhnlein, C. (2010). Simulating the future - responses of ecosystems, key species, and european provenances to expected climatic trends and events. Nov. Acta Leopoldina NF 384, 89-98. Available online at: http://www.bayceer.uni-bayreuth.de/bayceer/en/pub/pub/90118/Jentsch_ Beierkuhnlein.pdf

Knapp, A. K., Beier, C., Briske, D. D., Classen, A. T., Luo, Y., Smith, M. D., et al. (2008). Consequences of more extreme precipitation regimes for terrestrial ecosystems. BioOne 58, 811-821. doi: 10.1641/B580908

Kreyling, J., Wenigmann, M., Beierkuhnlein, C., and Jentsch, A. (2008). Effectsof extreme weather events on plant productivity and tissue die-back are modified by community composition. Ecosystems 11, 752-763. doi: 10.1007/s 1002 1-008-9 157-9

Larraya, L. M., Perez, G., Ritter, E., Pisabarro, A. G., and Ramirez, L. (2000). Genetic linkage map of the edible basidiomycete Pleurotus ostreatus. Appl. Environ. Microbiol. 66, 5290-5300. doi: 10.1128/AEM.66.12.5290-5300.2000

Lehninger, A. L., Cox, M. M., and Nelson, D. R. (2000). Principles of Biochemistry, $3 r d$ edn. New York, NY: Worth.

Manzoni, S., Schimel, J. P., and Porporato, A. (2012). Responses of soil microbial communities to water stress: results from a meta-analysis. Ecology 93, 930-938. doi: 10.1890/11-0026.1

Meehl, G. A., Zwiers, F., Evans, J., Knutson, T., Mearns, L., and Whetton, P. (2000). Trends in extreme weather and climate events: issues related to modeling extremes in projections of future climate change. Bull. Am. Meteorol. Soc. 81, 427-436. doi: 10.1175/1520-0477(2000)081<0427:TIEWAC>2.3.CO;2

Moyano, F. E., Manzoni, S., and Chenu, C. (2013). Responses of soil heterotrophic respiration to moisture availability: an exploration of processes and models. Soil Biol. Biochem. 59, 72-85. doi: 10.1016/j.soilbio.2013. 01.002

Ochoa-Hueso, R., Collins, S. L., Delgado-Baquerizo, M., Hamonts, K., Pockman, W. T., Sinsabaugh, R. L., et al. (2018). Drought consistently alters the composition of soil fungal and bacterial communities in grasslands from two continents. Glob. Chang. Biol. 24, 2818-2827. doi: 10.1111/gcb. 14113

Ogaya, R., and Peñuelas, J. (2004). Phenological patterns of Quercus ilex, Phillyrea latifolia, and Arbutus unedo growing under a field experimental drought. Ecoscience 11, 263-270. doi: 10.1080/11956860.2004.11682831

O'Gorman, P. A. O., and Schneider, T. (2009). The physical basis for increases in precipitation extremes in simulations of 21 st-century climate change. Proc. Natl. Acad. Sci. U.S.A. 106, 14773-14777. doi: 10.1073/pnas.0907610106

Panikov, N. S. (1999). Understanding and prediction of soil microbial community dynamics under global change. Agric. Ecosyst. Environ. Appl. Soil Ecol. 13, 295-176. doi: 10.1016/S0929-1393(98)00143-7

Pérez-González, J. A., van Peij, N. N., Bezoen, A., MacCabe, A. P., Ramón, D., and de Graaff, L. H. (1998). Molecular cloning and transcriptional regulation of the Aspergillus nidulans xlnD gene encoding a beta-xylosidase. Appl. Environ. Microbiol. 64, 1412-1419.

Pinheiro, J., Bates, D., DebRoy, S., Sarkar, D., and R Core Team. (2011). nlme: Linear and Nonlinear Mixed Effects Models. R package version 3.1-102.

Pontonio, E., Mahony, J., Di Cagno, R., O’Connell Motherway, M., Lugli, G. A., O'Callaghan, A., et al. (2016). Cloning, expression and characterization of a $\beta$ D-xylosidase from Lactobacillus rossiae DSM 15814(T). Microb. Cell Fact. 15, 72-72. doi: 10.1186/s12934-016-0473-Z

Pritsch, K., Luedemann, G., Matyssek, R., Hartmann, A., Schloter, M., Scherb, H., et al. (2005). Mycorrhizosphere responsiveness to atmospheric ozone and inoculation with phytophthora citricola in a phytotron experiment with spruce/beech mixed cultures. Plant Biol. 7, 718-727. doi: $10.1055 /$ s-2005-872972
R Core Team, (2012). R: A Language and Environment for Statistical Computing. Available online at: http://www.r-project.org

Regan, K., Stempfhuber, B., Schloter, M., Rasche, F., Prati, D., Philippot, L., et al. (2017). Spatial and temporal dynamics of nitrogen fixing, nitrifying and denitrifying microbes in an unfertilized grassland soil. Soil Biol. Biochem. 109, 214-226. doi: 10.1016/j.soilbio.2016.11.011

Richards, B. N. (1987). The Microbiology of Terrestrial Ecosystems. Essex: Longman Scientific \& Technical.

Rosenblad, A. (2009). J.J. Faraway: extending the linear model with R: generalized linear, mixed effects and nonparametric regression models. Comput. Stat. 24, 369-370. doi: 10.1007/s00180-009-0152-1

Sanaullah, M., Blagodatskaya, E., Chabbi, A., Rumpel, C., and Kuzyakov, Y. (2011). Drought effects on microbial biomass and enzyme activities in the rhizosphere of grasses depend on plant community composition. Appl. Soil Ecol. 48, 38-44. doi: 10.1016/j.apsoil.2011.02.004

Saner, P., Lim, R., Burla, B., Ong, R. C., Scherer-Lorenzen, M., and Hector, A. (2009). Reduced soil respiration in gaps in logged lowland dipterocarp forests. Forest Ecol. Manag. 285, 2007-2012 doi: 10.1016/j.foreco.2009.07.048

Sardans, J., and Peñuelas, J. (2010). Soil enzyme activity in a mediterranean forest after six years of drought this article has supplemental data published in the online version. Soil Sci. Soc. Am. J. 74, 838-851. doi: 10.2136/sssaj2009.0225

Schimel, J. P., and Bennett, J. (2004). Nitrogen mineralization: challenges of a changing paradigm. Ecology 85, 591-602. doi: 10.1890/03-8002

Schimel, J. P., and Schaeffer, S. M. (2012). Microbial control over carbon cycling in soil. Front. Microbiol. 3:348. doi: 10.3389/fmicb.2012.00348

Singhania, R. R., Patel, A. K., Sukumaran, R. K., Larroche, C., and Pandey, A. (2013). Role and significance of beta-glucosidases in the hydrolysis of cellulose for bioethanol production. Bioresour. Technol. 127, 500-507. doi: 10.1016/j.biortech.2012.09.012

Sowerby, A., Emmett, B. A., Tietema, A., and Beier, C. (2008). Contrasting effects of repeated summer drought on soil carbon efflux in hydric and mesic heathland soils. Global Change Biol. 14, 2388-2404 doi: 10.1111/j.1365-2486.2008. 01643.x

Stemmer, M., Gerzabek, M. H., and Kandeler, E. (1998). Organic matter and enzyme activity in particle-size fractions of soils obtained after lowenergy sonication. Soil Biol. Biochem. 30, 9-17. doi: 10.1016/S0038-0717(97) 00093-X

Walter, J., Grant, K., Beierkuhnlein, C., Kreyling, J., Weber, M., and Jentsch, A. (2012). Increased rainfall variability reduces biomass and forage quality of temperate grassland largely independent of mowing frequency. Agric. Ecosyst. Environ. 148, 1-10. doi: 10.1016/j.agee.2011.11.015

Warren, C. R. (2016). Do microbial osmolytes or extracellular depolymerisation products accumulate as soil dries? Soil Biol. Biochem. 98, 54-63. doi: 10.1016/j.soilbio.2016.03.021

Wierzbicka-Wos, A., Bartasun, P., Cie, H., and Kur, J. (2013). Cloning and characterization of a novel cold- active glycoside hydrolase family 1 enzyme with $\beta$-glucosidase, $\beta$-fucosidase and $\beta$-galactosidase activities. $B M C$ Biotechnol. 13:22. doi: 10.1186/1472-6750-13-22

Xiang, S.-R., Doyle, A., Holden, P. A., and Schimel, J. P. (2008). Drying and rewetting effects on $\mathrm{C}$ and $\mathrm{N}$ mineralization and microbial activity in surface and subsurface California grassland soils. Soil Biol. Biochem. 40, 2281-2289. doi: 10.1016/j.soilbio.2008.05.004

Conflict of Interest Statement: The authors declare that the research was conducted in the absence of any commercial or financial relationships that could be construed as a potential conflict of interest.

Copyright (C) 2019 Hammerl, Grant, Pritsch, Jentsch, Schloter, Beierkuhnlein and Gschwendtner. This is an open-access article distributed under the terms of the Creative Commons Attribution License (CC BY). The use, distribution or reproduction in other forums is permitted, provided the original author(s) and the copyright owner(s) are credited and that the original publication in this journal is cited, in accordance with accepted academic practice. No use, distribution or reproduction is permitted which does not comply with these terms. 